\title{
ANÁLISE DE RISCOS E/OU ACIDENTES NA ÁREA URBANA DE ILHÉUS-BAHIA
}

\author{
Patrícia Ferreira Silva ${ }^{(a)}$; Ednice de Oliveira Fontes Baitz ${ }^{(b)}$ \\ (a) Discente do curso de licenciatura em Geografia DCAA/UESC, Bolsista PROIC/CNPQ e-mail: \\ silva.ferreira.patricia@hotmail.com \\ (b) Docente do curso de Geografia DCAA/UESC e orientador, e-mail: ednice@uesc.br
}

Eixo: Geografia e Desastres Naturais

\begin{abstract}
Resumo
Com o crescimento das cidades na última metade do século passado, as cidades sofrem com problemas de infraestrutura advindos da falta de organização urbana. A intensificação da urbanização na modernidade gerou inúmeros problemas relacionados à qualidade e condições de vida humana nas cidades. No contexto da urbanização brasileira, nota-se que os espaços foram ocupados de modo a refletir as desigualdades sociais presentes na estrutura da nossa sociedade, este padrão de ocupação dos espaços continua nos dias atuais. Desta forma, este artigo objetiva analisar as condições de risco nas localidades Avenida Princesa Isabel e bairro Tapera da cidade de Ilhéus, identificando as principais causas de riscos naturais, tecnológicos e/ou sociais, através de levantamentos e análises documentais e bibliográficas; Pesquisa de campo para reconhecimento; Identificação das áreas de risco com base em mapeamento já realizado por Franco (2008), e sistematização dos dados da Coordenação Municipal de Defesa Civil da Prefeitura de Ilhéus.
\end{abstract}

Palavras chave: Áreas de risco; Riscos naturais; Riscos tecnológicos; Risco social; Urbanização.

\section{Introdução}

Os acidentes ambientais podem ocorrer de forma inesperada, afetando direta ou indiretamente a qualidade e condições de vida da comunidade envolvida causando impactos sociais e ao meio ambiente. Os acidentes ambientais podem ser caracterizados da seguinte forma: os desastres naturais, que são as ocorrências causadas por fenômenos da natureza independente das intervenções antrópicas; e os desastres tecnológicos que são as ocorrências provocadas por ações antrópicas.

Neste contexto as Análises Ambientais, segundo Ross (1998), visam atender as relações das sociedades humanas de um determinado território. A natureza neste caso é vista como recurso, ou seja, como suporte para a sobrevivência humana. Dentro desta perspectiva os estudos ambientais, de abordagem geográfica, têm sempre como referencial uma determinada sociedade (comunidade) que vive em um determinado território (município, estado, país, região, lugarejo, bacia hidrográfica etc.), onde desenvolvem suas atividades, com maior ou menor grau de complexidade, em função da intensidade dos vínculos internos e externos que mantêm no plano cultural, social e econômico. 
Segundo Botton (2013 Apud Carlos 2007, p. 56), o espaço urbano deve ser analisado de forma abrangente, envolvendo uma perspectiva histórica. "O espaço urbano como produto social, em constante processo de reprodução, $[. .$.$] onde tempos se sucedem e se justapõe montando um mosaico que lhe dá forma e impõe$ característica a cada momento".

Embora esses dois tipos de ocorrência sejam distintos quanto a sua causa, em determinados momentos pode haver uma relação entre os riscos ambientais e tecnológicos, um exemplo no contexto urbano da cidade de Ilhéus é, depois de uma forte chuva, ocorrer deslizamentos de terra e alagamentos expondo vidas humanas ao risco decorrente do uso e ocupação do solo de forma desordenada. Além dos danos diretos causados pelo fenômeno natural, há sua intensificação pelos impactos causados pela ocupação humana irregular. Todo risco pode ser qualificado como risco social, independente da causa, as consequências sempre serão sociais.

Sobre os riscos sociais, na interpretação de Vieillard-Baron ${ }^{1}$ (2007 apud DAGNINO; JÚNIOR 2007, p. 50):

\begin{abstract}
Os riscos sociais implicam uma pluralidade de atores e resultam da combinação de um grande número de variáveis, particularmente difíceis de serem consideradas ao mesmo tempo. Para descrevê-los e contribuir para a formação de políticas de prevenção, o geógrafo é interpelado em primeiro plano, mas ele deve se situar no encontro de várias especialidades: geografia física e humana, evidentemente, mas também, e de maneira não exclusiva, na intersecção dos ensinamentos da história, das ciências políticas, do direito e da psicossociologia.
\end{abstract}

A noção de risco está associada ao perigo, instabilidade e vulnerabilidade, pode estar presente em diversos setores da sociedade e por isto é alvo de diversas pesquisas no campo das ciências naturais e também sociais orientados para as causas e prevenções de acidentes. Com os avanços tecnológicos, industriais e urbanos em prol do desenvolvimento globalizado, modificou-se a natureza dos riscos, sendo estes cada vez mais complexos e difíceis de controlar. A análise de risco em Geografia, segundo Queiróz et al. (2006) está ligado a áreas de elevada concentração populacional ou em locais inadequados para as atividades humanas, o que se busca é a organização do espaço, a avaliação e gestão dos riscos.

Os acidentes naturais são em sua maioria de difícil prevenção, porém, no caso dos acidentes de origem tecnológica, os casos podem ser prevenidos. Dessa forma aplica-se o gerenciamento de riscos, ou seja, atua-se na probabilidade da ocorrência após análise dos fatores e características das condições do ambiente que favorecem ao risco como também nas consequências geradas pela ocorrência, razão pela qual este artigo trabalha na identificação das principais causas dos riscos naturais e tecnológicos e na prevenção dos mesmos. 


\section{Material e Métodos}

Os procedimentos metodológicos fundamentaram-se nos levantamentos e análises documentais e bibliográficas e no trabalho de campo. Os levantamentos e análises documentais e bibliográficas realizados na pesquisa se referem aos aspectos socioeconômicos e ambientais do Programa Habitar Brasil/ Bid Sub-programa de Desenvolvimento Institucional-DI, Plano Estratégico Municipal para assentamentos Sub-normais - PEMAS e Mapeamento e montagem de banco de dados das áreas de risco da cidade de Ilhéus realizado no período 2010 a 2016, elaborada pela Secretaria de Planejamento da Prefeitura Municipal de Ilhéus.

No processo de construção dos resultados obtidos com a pesquisa até o momento foram realizados dois trabalhos de campo para reconhecimento utilizando-se de formulário de observação baseado no Manual Técnico de Geomorfologia e dados do censo, com vistas a identificação das áreas de risco com base em mapeamento já realizado por Franco (2008) e levantamento fotográfico, bem como coleta e sistematização dos dados da Coordenação Municipal de Defesa Civil (COMDEC) da Prefeitura de Ilhéus.

É neste contexto que se atualizar os mapas de risco existentes para cidade de Ilhéus, além de estimar a extensão e a intensidade do fenômeno, com o auxílio do sistema de informação geográfica (SIG) que tem sido utilizado em pesquisas sociais com o objetivo de obter um conhecimento mais eficiente da qualidade de vida urbana nos territórios usados. O resultado principal é a elaboração/atualização de mapas que identifiquem os problemas urbanos e ajudem na construção de uma tipologia a nível local. Essas informações serão apresentadas a sociedade civil organizada através de conferencias em conselhos municipais bem como entregues a Defesa Civil do município.

\section{Resultados e Discussões}

\section{1 - Caracterização da Área de Estudo}

A cidade de Ilhéus é caracterizada por duas feições geomorfológica. Um conjunto de colinas ou mamelões, que são áreas onduladas com topos arredondados, de declividade suave, e uma área extensa de tabuleiros, que corresponde aos locais mais elevados com topos quase planos e cortados por vales profundos escavados por leitos de antigos rios, que originam encostas escarpadas constituídas de um 


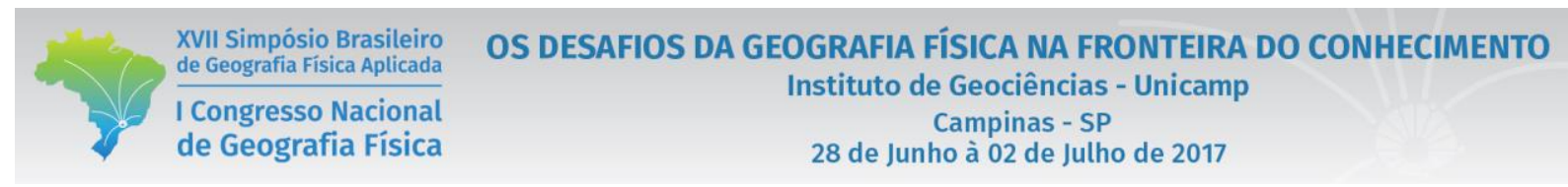

espesso manto argiloso, formado de gnaisses, granulitos e rochas básicas. Assim, Ilhéus possui uma paisagem com características peculiares no que se refere à compartimentação do relevo. De forma geral, o município apresenta em seu recorte territorial o Domínio Morfoclimático dos Mares de Morros (AB’SÁBER, 1969), Planalto Pré-Litorâneo, Planalto Costeiro, Tabuleiros Costeiros e Planície Costeira. $\mathrm{Na}$ área urbana, o relevo de Ilhéus apresenta como feições morros, colinas, outeiros e fundos de vale.

Em outubro do ano de 2016, foi realizada visita de campo a fim de verificar os registros de ocorrências de movimentos de massa sucedidos na área urbana de Ilhéus- BA, fornecidos pela Coordenação Municipal de Defesa Civil (COMDEC). As áreas visitadas destacadas na figura 1, são: Avenida Princesa Isabelencostas e área de manguezal e Bairro Tapera - encostas.

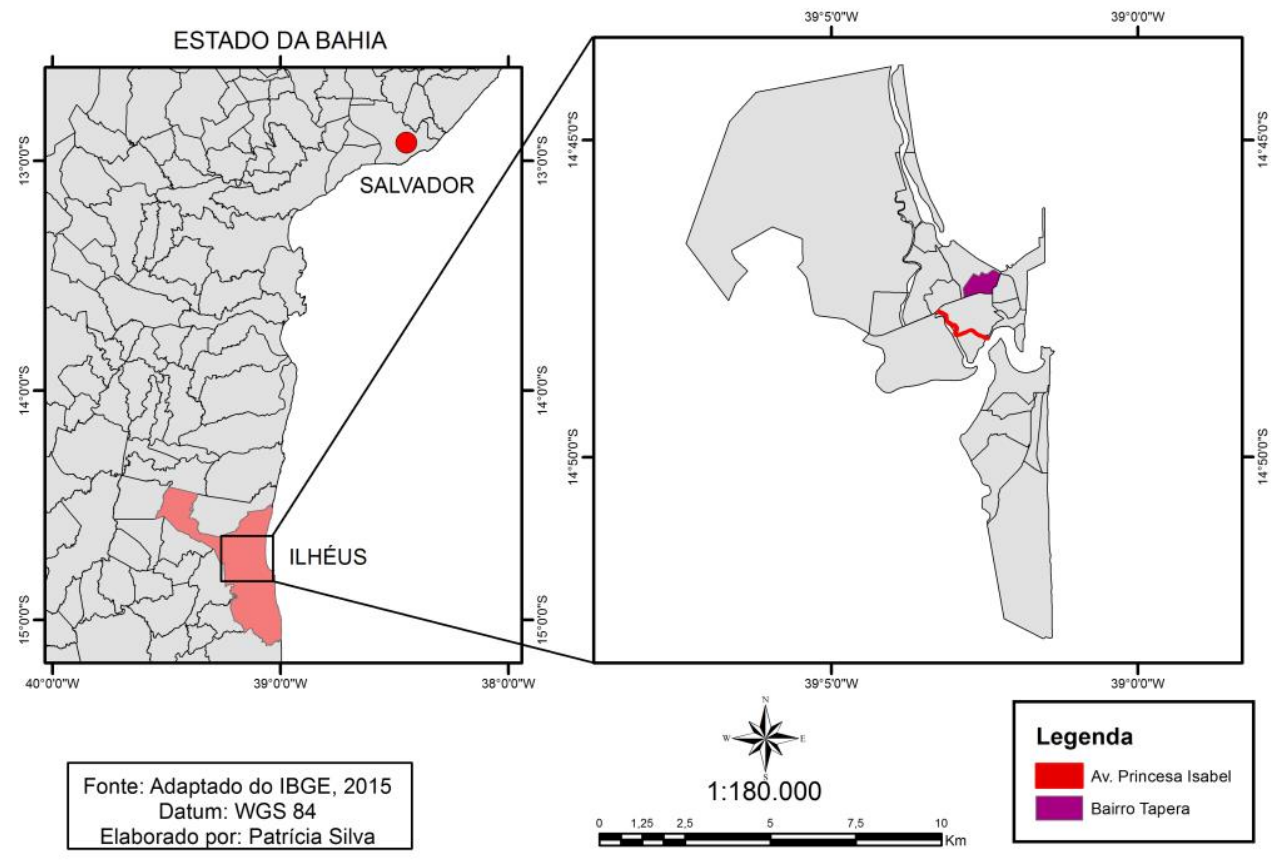

Figura 1 - Localização da Avenida Princesa Isabel e bairro Tapera Fonte: Dados de Pesquisa, 2016.

Em Franco (2008) diz que: A Lei Federal nº. 6.766/79 (BRASIL, 2006) determina que em áreas com declividade acima de $30 \%$ não é permitida a ocupação por moradias, uma vez que essas áreas são consideradas bastante declivosas, o que dificulta a urbanização, além de haver maior suscetibilidade à erosão e instabilidade das encostas quando retirada a vegetação para dar lugar a novas moradias. Até 30\% é o valor máximo permitido por lei para a ocupação de encostas, acima desse valor só é permito após liberação através de laudo técnico, fato este que não ocorre na cidade de Ilhéus, as encostas são ocupadas descumprindo a lei e com a omissão e/ou conivência do poder público, além da maioria dos morros e encostas serem ocupados pela população pobre que não detêm de condições para efetuar a construção de 


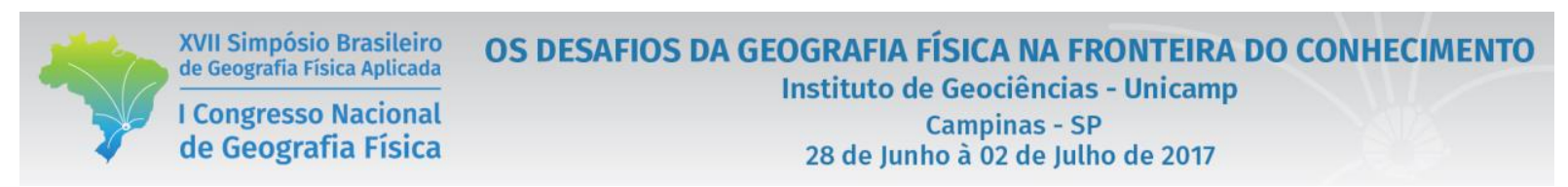

suas moradias dentro das normas de construção civil. A declividade é um fator determinante na identificação de áreas de risco, na cidade de Ilhéus como mostra na figura 2, é composta por morros em sua maioria com declividade até $30 \%$, ou seja, dentro dos limites permitidos por lei, o que não assegura que área esteja livre de acidentes pois desconsidera outros fatores naturais e antrópicos que podem influenciar na intensificação do risco.

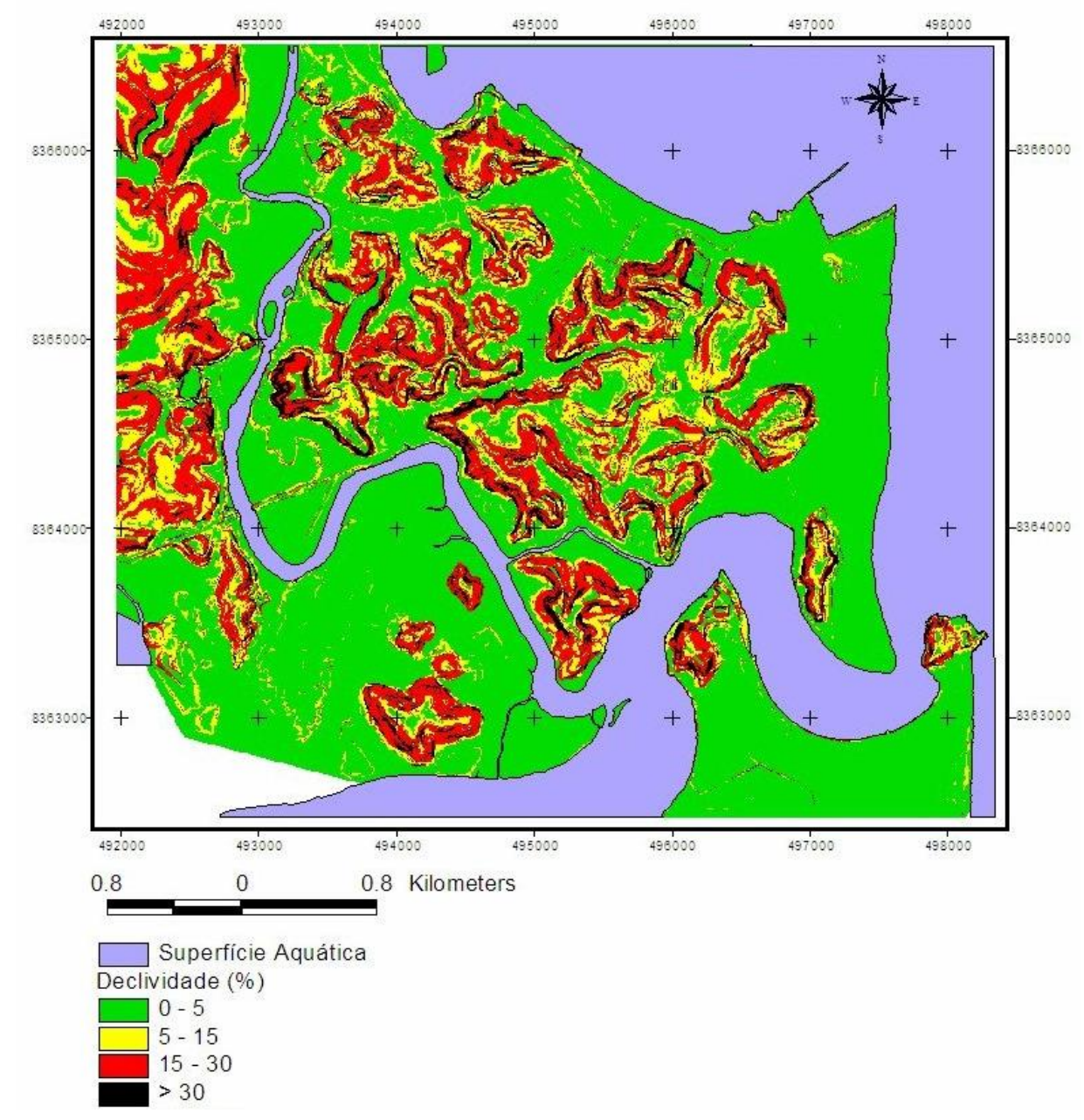

Figura 2 - Declividade da área urbana de Ilhéus

Fonte: FRANCO, G. 2008

O relevo da cidade de Ilhéus, figura 3, é composto basicamente por morros e planície, o que exige organização e planejamento em sua ocupação urbana, ação essa que não é efetuada pelo poder público. A população está sujeita ao perigo dos deslizamentos nos morros e aos alagamentos na planície, pois a cidade é banhada pelo mar e possui estuário, área de proteção permanente que já se encontra densamente ocupada. 


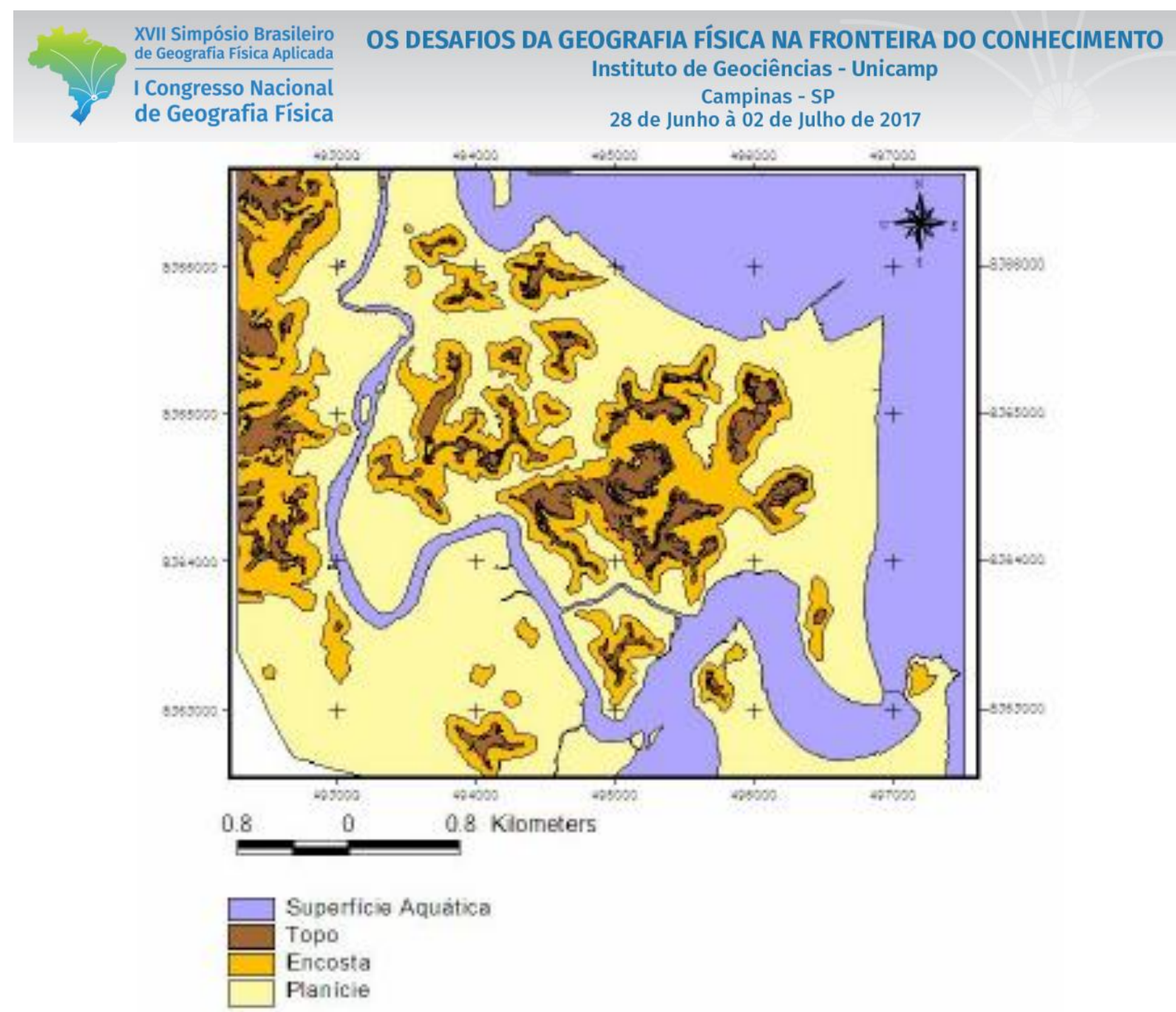

Figura 3 - Relevo da área urbana de Ilhéus Fonte: FRANCO, G. 2008

\section{2 - Ocupação Urbana $X$ áreas de risco}

Segundo afirma Nunes² (1994 apud FRANCO, 2008, p. 3), na história do Brasil, principalmente na faixa litorânea, as ocupações se deram nos cumes e encostas, mas o adensamento do processo de urbanização deu-se a partir da década de 70, aliado à falta de recursos e de políticas habitacionais e uma crise econômica que atingiu todo o país, contribuíram para os movimentos migratórios e consequentemente a aceleração da ocupação das áreas de encostas, principalmente pelas populações pobres, resultando em risco para milhares de famílias.

As ocupações das áreas consideradas de risco em Ilhéus datam diferentes períodos (Tabela 1), a partir da década de 1940 sendo algumas de ocupação mais recentes por volta da década de 90 . O período de maior adensamento populacional se deu a partir da década de 70, por conta dos movimentos migratórios do campo para a cidade (êxodo rural), que se sucedeu com muita intensidade, visto que, a cidade nesse período exerceu grande atração sobre os trabalhadores rurais à procura de emprego nas lavouras de cacau. 
Tabela I- Dados de ocupação e populacionais das áreas de risco bairro Tapera e Avenida Princesa Isabel

Z

\section{Alto do \\ Socorro}

(Av. 1940

73.144

1.053

3,20

293

219

4,12

Princesa

Isabel)

\begin{tabular}{lccccccc}
\hline Tapera & 1940 & 106.731 & 912 & 4,23 & 253 & 108 & 3,30 \\
\hline $\begin{array}{l}\text { Alto do } \\
\text { Cacau/Ube } \\
\text { rlândia } \\
\text { (Bairro }\end{array}$ & 1960 & 117.721 & 1.251 & 5,47 & 348 & 114 & 3,58 \\
\begin{tabular}{l} 
Tapera) \\
\hline
\end{tabular} & & & & & & & \\
\hline
\end{tabular}

Fonte: Secretaria do Planejamento da Prefeitura Municipal de Ilhéus, 2015.

Com a crise cacaueira no fim da década de 80 e início da década de 90, as taxas de população rural e urbana tiveram variâncias significativas decorrentes da crise cacaueira. A população sem emprego migrou para a cidade a procura de melhores condições de vida, ocasionando seu "crescimento acelerado e o surgimento de problemas urbanos e sociais semelhantes aos das grandes metrópoles do país", segundo Soares (2006, p.349) este processo de urbanização sofrido, representado na tabela II, originou entre 1991 e 2000 o aumento da população urbana, que cresceu 8,52 \%, já entre 2000 e 2010 houve o crescimento de 10, 45\%. A predominância da população urbana sobre a população rural é evidente no município de Ilhéus, em sua área urbana, as encostas e morros foram recebendo a população excedente e pobre da cidade.

Tabela II - População total, rural e urbana de Ilhéus/BA

\begin{tabular}{lrrrrrr}
\hline População & $\begin{array}{r}\text { População } \\
(\mathbf{1 9 9 1 )}\end{array}$ & $\begin{array}{r}\text { \% do Total } \\
(\mathbf{1 9 9 1 )}\end{array}$ & $\begin{array}{r}\text { População } \\
(\mathbf{2 0 0 0 )}\end{array}$ & $\begin{array}{r}\text { \% do Total } \\
(\mathbf{2 0 0 0})\end{array}$ & $\begin{array}{r}\text { População } \\
(\mathbf{2 0 1 0})\end{array}$ & $\begin{array}{r}\text { \% do Total } \\
(\mathbf{2 0 1 0})\end{array}$ \\
População total & 220.834 & 100,00 & 219.596 & 100,00 & 184.236 & 100,00 \\
População urbana & 144.232 & 65,31 & 162.125 & 73,83 & 155.281 & 84,28 \\
População rural & 76.602 & 34,69 & 57.471 & 26,17 & 28.955 & 15,72 \\
\hline
\end{tabular}

Fonte: PNUD, Ipea e FJP, Censo 1991, 2000 e 2010.

Na figura 4, os pontos em vermelho indicam a localização da área de estudo, as já citadas Avenida Princesa Isabel e o bairro da Tapera. As áreas no mapa de cor mais escura indicam alta densidade populacional, essas áreas são referentes aos topos de morro existentes na área urbana de Ilhéus, ou seja, 
mais da metade da população urbana de Ilhéus reside em áreas de risco a escorregamento de massa. Vale ressaltar que essa população residente nos morros é pobre, suas habitações são informais, o acesso a água, condições sanitárias, segurança e infraestrutura lhes são negados, dando a eles segundo Davis (1946, p. 33) a definição clássica de favela adotada pela ONU no ano de 2002, "caracterizada por excesso de população, habitações pobres ou informais, acesso inadequado a água potável e condições sanitárias e insegurança da posse da moradia".

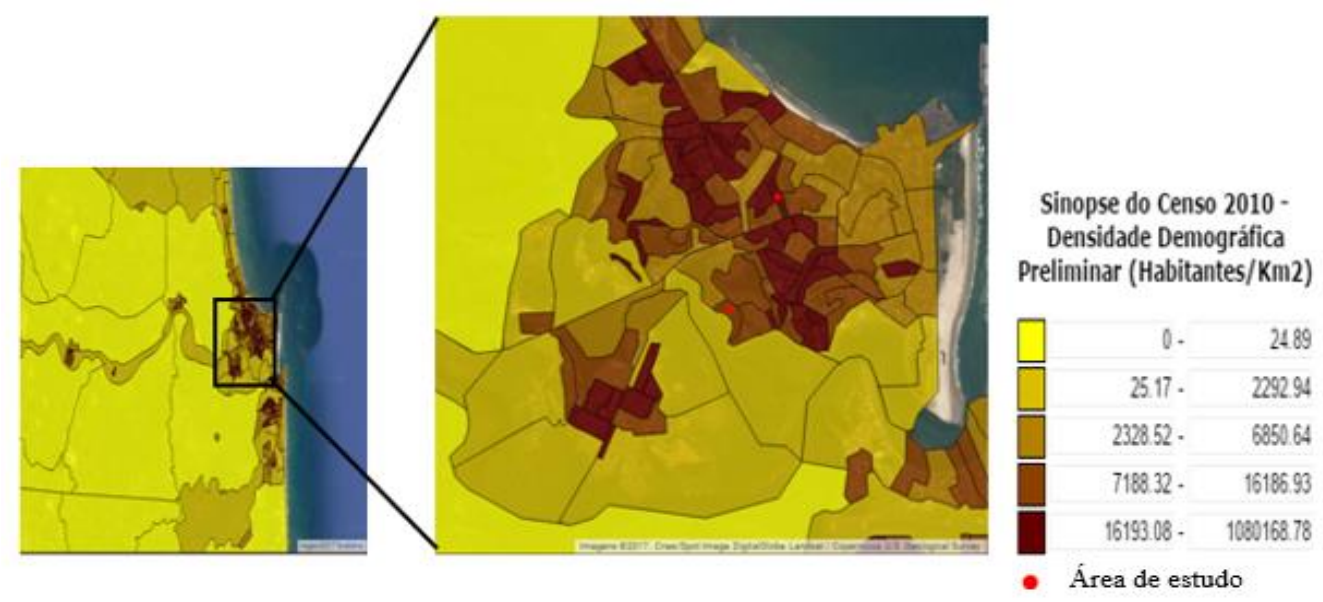

Figura 4 - Densidade demográfica dos bairros de Ilhéus Fonte: IBGE, Sinopse por setores, Censo 2010.

\subsection{Principais condicionantes de degradação das áreas de risco em Ilhéus}

Os condicionantes de degradação das áreas consideradas de risco presentes na área urbana de Ilhéus como as encostas, topos de morro e áreas de mangue, são os elementos do meio físico que associados a influência antrópica, contribuem para o desencadeamento e potencialização do processo de instabilidade. Segundo Franco (2008) os condicionantes são favoráveis ao desencadeamento do escorregamento e/ou alagamentos devido às condições topográficas e de carência de infraestrutura. Estes condicionantes foram estabelecidos por meio de visita de campo e avaliação de características estruturais e dos condicionantes ao risco, tais como: ausência de drenagem, cortes no terreno, cicatrizes de escorregamento, entre outros.

\subsubsection{Retirada da vegetação}

O município de Ilhéus se encontra inserido no bioma mata atlântica, as áreas de encostas da cidade eram cobertas por essa vegetação que, com o crescimento urbano, foram suprimidas para a ocupação e reprodução do espaço urbano. A ocupação desordenada destas áreas, quase sempre ocorrem em patamares, propiciam com a retirada da vegetação a exposição das encostas às intempéries climáticas, 
principalmente água da chuva, tendo como resultado mais freqüente a erosão e o deslizamentos de terra. Atualmente a vegetação encontrada nessas áreas limita-se a uma vegetação secundária, como pequenos arbustos e vegetação rasteira (Figura 5).

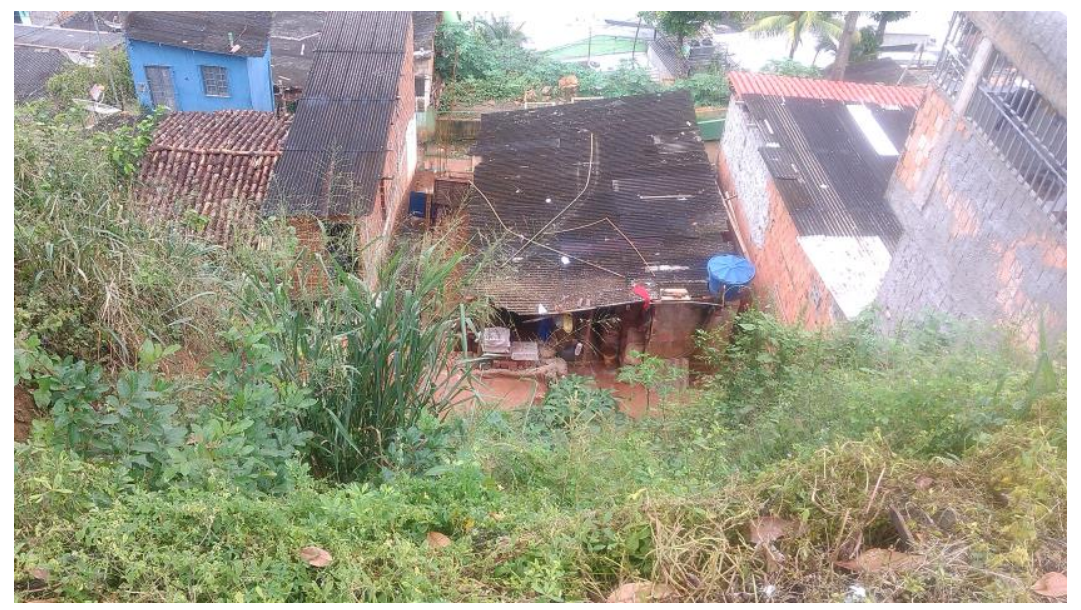

Figura 5 - Vegetação em encosta no bairro Tapera.

Fonte: Pesquisa de campo, 2016.

\subsubsection{Ausência de drenagem}

Os deslizamentos de terra na cidade de Ilhéus, estão quase sempre associados a períodos chuvosos, e são potencializados pelo lançamento de águas servidas, esgoto ou vazamento de tubulações ao longo da encosta. Grande parte das áreas de risco de Ilhéus não possui sistema de drenagem das águas da chuva ou até mesmo sistema de coleta de esgoto, a maioria das residências possui fossas sépticas. A ausência desses serviços básicos de saneamento favorece a infiltração das águas que associado à ausência de vegetação, provoca o aumento significativo na velocidade do escoamento superficial e/ou subsuperficial provocando a ocorrência de possíveis deslizamentos. A figura 6 mostra uma das poucas obras de contenção existentes na cidade, este ponto da foto está localizado no morro da Tapera, ao lado, abaixo esta uma das avenidas mais importantes e principal porta de entrada para a cidade de quem chegam pela BR 415, rodovia Ilhéus/Itabuna. Existem outras áreas da cidade que sofreram intervenções, mas na sua maioria realizadas de modo imediatista sem um planejamento e de forma pontual, ou seja, quase sempre em caráter de emergência, desconsiderando ações de cunho preventivo. 


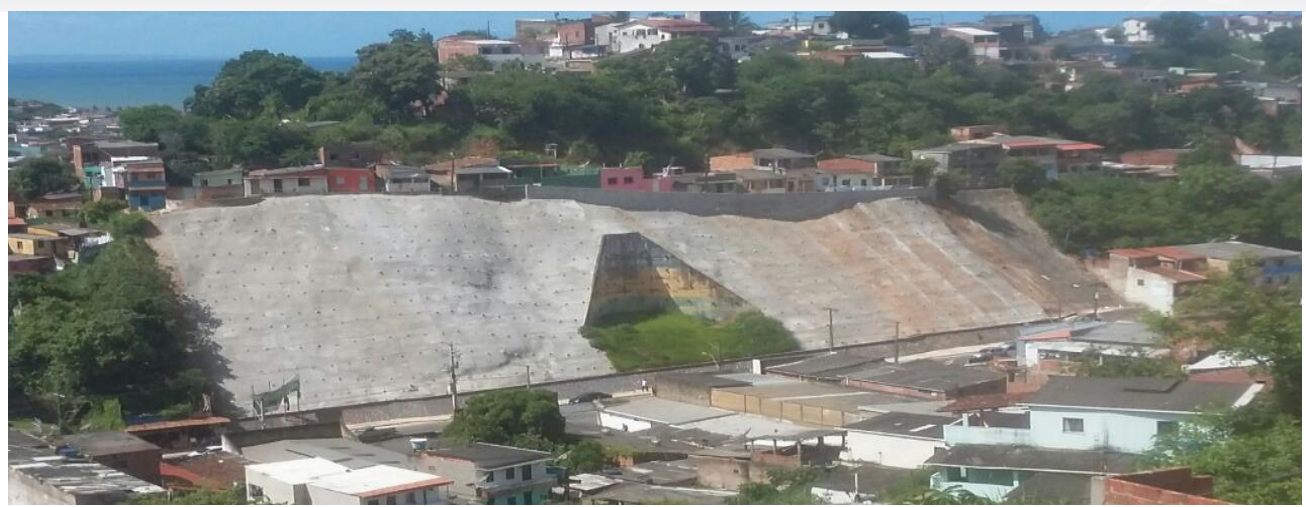

Figura 6 - Obra de contenção da Encosta do morro da Tapera

Fonte: Dados da Pesquisa, 2016.

\subsubsection{Lixo e entulho}

A Avenida Princesa Isabel se encontra inserida no fundo de vale, onde de um lado há a presença de morros com encostas íngremes e do outro o mangue, um ambiente ecótono que liga o ambiente marinho ao terrestre onde sua preservação é de extrema importância para o equilíbrio da fauna e flora desses ambientes.

O lixo descartado de forma incorreta nas encostas se acumula e acaba gerando o chorume, que mesmo em pouca quantidade é um líquido malcheiroso que nestas circunstâncias acaba por infiltrar no solo e associam-se as águas lançadas pelos encanamentos de esgotos feitos pelos próprios moradores e as águas pluviais, todos estes fatores contribuem de forma conjunta ou não para a sobrecarga do solo deixando-o saturado. Vale ressaltar que o lixo também dificulta a aeração dos solos mantendo sua umidade alta por mais tempo. Nesse sentido, na margem direita do rio (figura 7), percebemos que a vegetação ainda se encontra em bom estado, trata-se da área de mangue, na margem esquerda há maior supressão devido à ocupação urbana. No trabalho de campo, pode-se observar a presença de entulhos e lançamento de esgoto in natura no Rio Almada, sobretudo na proximidade da área de manguezal com as moradias. Que chega acerca de 5 metros aproximadamente. A proximidade desta área com o Rio também a torna suscetível a alagamentos. 


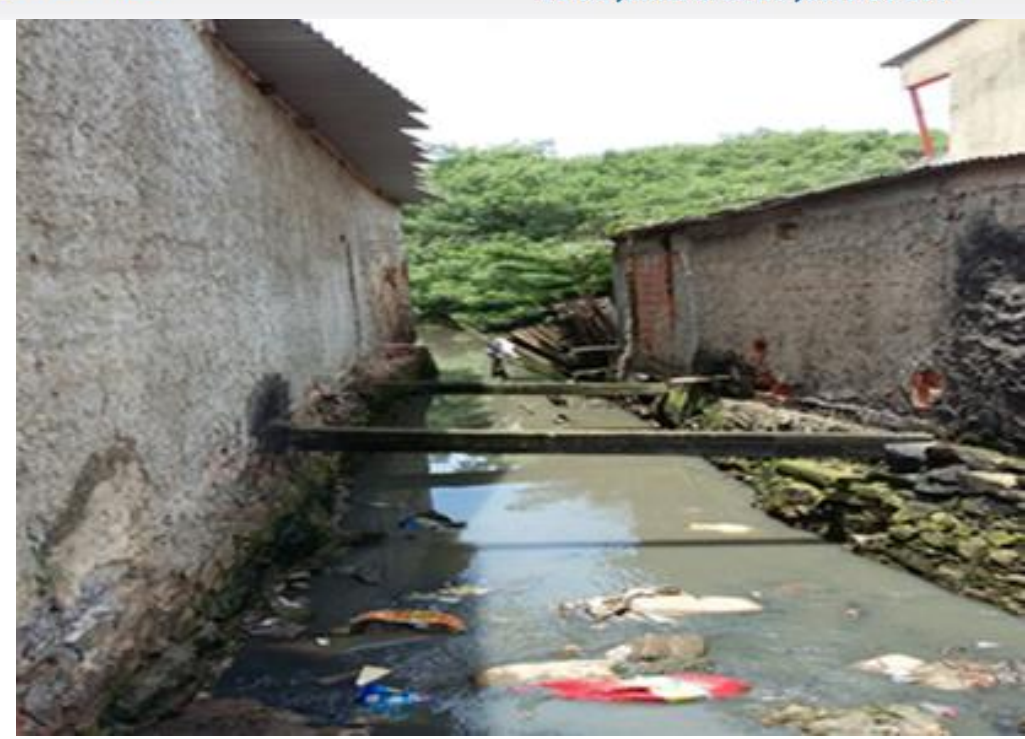

Figura 7 - Esgoto residencial lançado no mangue

\section{Considerações Finais}

No contexto da urbanização Ilheense, nota-se com base nas análises realizadas ate o presente, uma caracterização dos condicionantes de degradação urbana das áreas consideradas de risco, identificando as principais causas de riscos naturais e sociais, neste caso, ocupação de áreas de mangue, sujeitas a inundação e encosta íngremes, estas áreas foram densamente ocupadas e hoje representam áreas de risco para a população que habita estes territórios de modo a refletir as desigualdades sociais presentes na estrutura da sociedade. Sendo assim, a análise dos riscos passa por desafios, a globalização tornou o processo de urbanização em todo o mundo cada vez mais intenso, rápido e complexo, principalmente nos países periféricos que tem se urbanizado de forma mais intensa que os países desenvolvidos. Além disso, a análise dos riscos incorpora as ciências naturais e sociais, o que torna fundamental o estudo de como a sociedade interage com o ambiente para uma melhor eficácia em ações de gerenciamento de risco.

Em Ilhéus, a partir dos anos 80, as taxas de população rural e urbana tiveram variâncias significativas em função do êxodo rural decorrente da crise cacaueira. Esta mão de obra excedente migrou para a cidade a procura de melhores condições de vida, muitas dessas pessoas foram e continuam sendo marginalizadas pelo sistema social e são obrigadas a encontrar moradia em áreas impróprias. As áreas mais seguras, frente a geomorfologia existente e em função da especulação imobiliária, já estão ocupadas pelas classes de maior poder aquisitivo. Nesse contexto, surgem as áreas de risco, que antes do processo de urbanização eram apenas áreas suscetíveis pois naturalmente apresentam restrições a ocupação humana. 
As ocorrências de acidentes ambientais no sítio urbano de Ilhéus, via de regra, estão associados a interferências impostas pela ocupação humana desorganizada, a exemplo de cortes abruptos e aterros, ausência de drenagem pluvial, deposição de lixo, retirada da cobertura vegetal natural, dentre outros, aliada aos processos naturais. Desta maneira, as encostas com ocupações que muitas vezes são fruto de uma ocupação não planejada, devem receber atenção redobrada do poder público, através de investimentos em medidas estruturais e não-estruturais para assim garantir a segurança dos moradores.

\section{Agradecimentos}

Ao Conselho Nacional de Desenvolvimento Científico e Tecnológico pelo financiamento da pesquisa.

\section{Bibliografia}

AB`SÁBER, A.N. Um Conceito de Geomorfologia a Serviço das Pesquisas sobre o Quaternário. São Paulo, Geomorfologia, n. 18, p.1-23, 1969.

ATLAS DO DESENVOLVIMENTO HUMANO DO BRASIL. Ilhéus, BA. Disponível em: <http://www.atlasbrasil.org.br/2013/pt/perfil_m/ilheus_ba>. Acesso em: 08 fev. 2017.

BRASIL. Lei Lehmann: Lei 6.766, em 19 de dezembro de 1979. Disponível em: <http://www.senado.gov.br/sf/legislacao/>. Acesso em: 17 de fev. 2017.

CARLOS, Ana Fani Alessandri. O Espaço Urbano: Novos Escritos sobre a Cidade. São Paulo: FFLCH, 2007, 123p. Inclui bibliografia. 1. Espaço 2. Cidade 3.

CERRI, L. E. S.; NOGUEIRA, F. R. Mapeamento e gestão de riscos de escorregamentos em áreas de assentamentos precários. In: GUIMARÃES, S. T. L.; JÚNIOR, S. C.; GOGOY, M. B. R. B.; TAVARES, A. C. (Orgs.). Gestão de

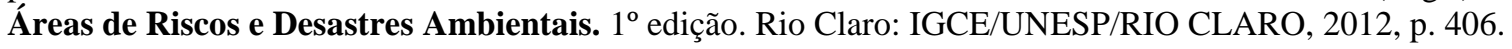

COORDENAÇÃO MUNICIPAL DE DEFESA CIVIL. PREFEITURA DE ILHÉUS- COMDEC. Registro de ocorrências de movimentos de massa sucedidos na área urbana de Ilhéus-BA nos períodos de janeiro de 2002 a julho de 2014.

DAGNINO, R. S.; JÚNIOR, S. C. Risco Ambiental: conceitos e aplicações. Climatologia e estudos da Paisagem, Vol. 2 - n.2 - julho/dezembro/2007, p. 50.

DAVIS, M, 1946. Planeta Favela. São Paulo: Boitempo, 2006. p. 272

FRANCO, G. B. Risco a escorregamento de encostas do sítio urbano de Ilhéus (BA) como contribuição ao planejamento urbano. 159 f. Dissertação (Mestrado Desenvolvimento e Meio Ambiente) - Universidade Estadual de Santa Cruz, Ilhéus, 2008.

INSTITUTO BRASILEIRO DE GEOGRAFIA E ESTATÍSTICA-IBGE. Sinopse por setores. Disponível em: <http://www.censo2010.ibge.gov.br/sinopseporsetores/?nivel=st>. Acesso em 06 de fev. 2017.

Manual técnico de geomorfologia / IBGE, Coordenação de Recursos Naturais e Estudos Ambientais. - 2. ed. - Rio de Janeiro: IBGE, 2009.182 p.

NUNES, C. M. et al. O cadastro das áreas de risco e a carta geotécnica a serviço de um trabalho interdisciplinar. In: CONGRESSO BRASILEIRO DE GEOLOGIA, 38, 1994, Balneário de Camboriú. Anais... Balneário de Camboriú: CBG, 1994. p. 492-494.

OLIVEIRA, E. L. A. Áreas de risco geomorfológico na bacia hidrográfica do Arroio Cadena, Santa Maria/RS: Zoneamento e Hierarquização. Dissertação (Mestrado) Universidade Federal do Rio Grande do Sul, Porto Alegre, julho de 2004. P. 147. 
QUEIRÓZ, M.; VAZ, T.; PALMA, P. Uma reflexão a propósito do risco. Centro de Estudos Geográfico:

Faculdade de Letras da Universidade de Lisboa, 2006, p. 23.

ROSS, J. L. S. Geomorfologia: ambiente e planejamento. 3. ed. São Paulo: Contexto, 1996.

SOARES, P. R. Cidades Médias e aglomerações urbanas: A nova organização do espaço regional no sul do Brasil. In: SPOSITO, E. S.; SPOSITO, M. E. B.; SOBARZO, O. (Orgs.). Cidades Médias: produção do espaço urbano e regional. $1^{\circ}$ edição. São Paulo: Editora Expressão Popular, 2006. 376 p.

VIEILLARD-BARON, H. Os riscos sociais. In: VEYRET, Y. (Org.) Os Riscos: o homem como agressor e vítima do meio ambiente. São Paulo: Contexto, 2007. p. 275-316. 